\title{
Early Events of the Reaction Elicited by CSF-470 Melanoma Vaccine Plus Adjuvants: An In Vitro Analysis of Immune Recruitment and Cytokine Release
}

\author{
María B. Pampena1, María M. Barrio', Estefanía P. Juliá1, Paula A. Blanco, \\ Erika M. von Euw ${ }^{2}$, José Mordoh ${ }^{1,3,4+}$ and Estrella Mariel Levy ${ }^{1 \text { *t }}$
}

'Centro de Investigaciones Oncológicas-Fundación Cáncer, Buenos Aires, Argentina, ${ }^{2}$ UCLA JCCC-Translational Oncology Research Labs, Los Angeles, CA, United States, ${ }^{3}$ Instituto Médico Especializado Alexander Fleming, Buenos Aires, Argentina, ${ }^{4}$ Fundación Instituto Leloir, IIBBA-CONICET, Buenos Aires, Argentina

OPEN ACCESS

Edited by:

Sherven Sharma,

VA Greater Los Angeles Healthcare System (NHA), United States

Reviewed by: William L. Redmond,

Earle A. Chiles Research Institute,

United States

Nejat K. Egilmez,

University of Louisville,

United States

${ }^{*}$ Correspondence:

Estrella Mariel Levy estrellamlevy@yahoo.com.ar

tThese authors have contributed equally to this work.

Specialty section: This article was submitted

to Cancer Immunity and Immunotherapy,

a section of the journal

Frontiers in Immunology

Received: 27 July 2017 Accepted: 03 October 2017 Published: 23 October 2017

Citation:

Pampena MB, Barrio MM, Juliá EP Blanco PA, von Euw EM, Mordoh J and Levy EM (2017) Early Events of the Reaction Elicited by CSF-470 Melanoma Vaccine Plus Adjuvants: An In Vitro Analysis of Immune Recruitment and Cytokine Release.

Front. Immunol. 8:1342. doi: 10.3389/fimmu.2017.01342
In a previous work, we showed that CSF-470 vaccine plus bacillus Calmette-Guerin (BCG) and granulocyte macrophage colony-stimulating factor (GM-CSF) as adjuvants resulted in a significant benefit in the distant metastasis-free survival when comparing vaccinated vs. IFN- $\alpha 2$ b-treated high-risk cutaneous melanoma patients in a Phase II study. Immune monitoring demonstrated an increase in anti-tumor innate and adaptive immunities of vaccinated patients, with a striking increase in IFN- $\gamma$ secreting lymphocytes specific for melanoma antigens (Ags). In an effort to dissect the first steps of the immune response elicited by CSF-470 vaccine plus adjuvants, we evaluated, in an in vitro model, leukocyte migration, cytokine production, and monocyte phagocytosis of vaccine cells. Our results demonstrate that leukocytes recruitment, mostly from the innate immune system, is an early event after CSF-470 vaccine plus BCG plus GM-CSF interaction with immune cells, possibly explained by the high expression of CCL2/MCP-1 and other chemokines by vaccine cells. Early release of TNF- $\alpha$ and IL-1 $\beta$ pro-inflammatory cytokines and efficient tumor Ags phagocytosis by monocytes take place and would probably create a favorable context for Ag processing and presentation. Although the presence of the vaccine cells hampered cytokines production stimulated by BCG in a mechanism partially mediated by TGF- $\beta$ and IL-10, still significant levels of TNF- $\alpha$ and IL-1 $\beta$ could be detected. Thus, BCG was required to induce local inflammation in the presence of CSF-470 vaccine cells.

Keywords: immunotherapy, melanoma vaccine, innate immunity, leukocyte recruitment, pro-inflammatory cytokines, bacillus Calmette-Guerin, adjuvants

\section{INTRODUCTION}

Cutaneous melanoma (CM) originates from melanocytes, and it is an immunogenic tumor, as suggested by the presence of regression areas observed in primary tumors and by the correlation between "brisk" lymphocytic infiltrates and longer survival (1). In recent years, immunotherapy became a promising option and blockade of immune checkpoints with monoclonal antibodies (MAbs) has shown relevant clinical results in metastatic disease, further implying the importance of lymphocytes

Abbreviations: MAb, monoclonal antibodies; Ags, antigens; BCG, bacillus Calmette-Guerin; CM, cutaneous melanoma; DCs, dendritic cells; HD, healthy donor, PBMCs, Peripheral blood mononuclear cells; PBS, phosphate saline buffer; GM-CSF, recombinant human granulocyte macrophage colony-stimulating factor; LN, lymph node. 
to control tumor progression (2-4). On the other hand, vaccination approaches to foster the immune system reactivity have had limited success in CM patients, probably because most studies were performed treating patients with advanced disease using a few single antigens (Ags) as immunogens (5-7). In view of the multiplicity of mutated and non-mutated Ags present in $\operatorname{CM}(8,9)$, our approach to vaccination has been: (i) to use irradiated whole tumor cells as a source of multiple tumor Ags, providing the immune system with the opportunity to process them without a priori selection by the investigator (10-12), and (ii) to overcome the possible immune tolerance toward tumor cells by adding bacillus Calmette-Guerin (BCG) and granulocyte macrophage colony-stimulating factor (GM-CSF) as adjuvants. We have previously determined, in Phase I clinical trial in which $20 \mathrm{CM}$ patients were treated with fixed doses of an allogeneic vaccine plus BCG and variable doses of GM-CSF that $400 \mu \mathrm{g}$ of GM-CSF per vaccination (divided into four daily injections) was optimal (10). Strikingly, $64 \%$ of the stage III CM patients from that study remain relapse-free after a median follow-up $>$ 192 months. A closely similar vaccine (CSF-470) was assayed in Phase II clinical study, in which $31 \mathrm{CM}$ patients stage IIB, IIC, and III were randomized to receive CSF-470 vaccine plus BCG and GM-CSF versus medium-dose IFN- $\alpha 2 b$ (13). CSF-470 is a mixture of four CM cell lines to which whole exome sequencing and mRNA expression analysis were performed; the cell lines are heterogeneous for HLA class I haplotype and for expression of melanocytic differentiation Ags $(11,13)$. In that study, with a mean and maximum follow-up of 39.4 and 83 months, respectively, a significant benefit in the distant metastasis-free survival of vaccinated patients was observed $(p=0.022)$ as compared to IFN- $\alpha 2 b$ (medium dose). Immune monitoring demonstrated an increase in anti-tumor innate and adaptive immunity of vaccinated but not in IFN- $\alpha 2 b$-treated patients with a striking increase in IFN- $\gamma$-secreting lymphocytes specific for melanoma Ags (13). Therefore, a $\mathrm{TH}_{1}$ immune response was induced by this vaccination system. Despite numerous clinical studies demonstrating BCG and GM-CSF abilities to activate immune responses (14-17), we could not find any reports in which the in vitro interactions between tumor cells and these adjuvants were studied. To dissect the first steps of such interactions we evaluated, in an in vitro model, leukocyte migration, cytokine production and monocyte phagocytosis. Our results demonstrate that leukocyte recruitment, mostly from the innate immune system, is an early event after CSF-470 vaccine plus BCG plus GM-CSF interaction with immune cells. In fact, CCL2/MCP-1 chemokine released by CSF-470 vaccine cells could account, at least partially, for monocytes and lymphocytes attraction. Early release of TNF- $\alpha$ and IL- $1 \beta$ pro-inflammatory cytokines and efficient tumor Ags phagocytosis by monocytes also occurs and would favor subsequent Ag processing and presentation. Finally, although the presence of the vaccine cells partially inhibited cytokines production stimulated by BCG, still significant levels of TNF- $\alpha$ and IL- $1 \beta$ could be detected. Thus, BCG was required to induce local inflammation in the presence of CSF-470 vaccine cells.

\section{MATERIALS AND METHODS}

\section{CSF-470 Vaccine Cells}

The CSF-470 vaccine consists of lethally gamma-irradiated cells (apoptotic/necrotic) derived from four CM cell lines established in-house from human metastatic melanoma tumors. The cell lines MEL-XY1, MEL-XY2, MEL-XY3 and MEL-XX4 were grown in a GMP core facility at the Centro de Investigaciones Oncológicas-FUCA and were cultured as previously described (11). Vaccine preparation was formerly described (13). In all in vitro experiments irradiated CSF-470 cells were used (CSF-470 vaccine).

\section{RNASeq}

RNASeq was performed for each viable cell line with the sequencing platform Illumina Hiseq 4000, with more than $20 \mathrm{M}$ highquality single-end reads per sample (BGI Americas). Quality control of reads was performed with FASTX-Toolkit ${ }^{1}$ and FastQC. ${ }^{2}$ Reads were aligned to the latest human $\mathrm{Hg} 38$ reference genome using the STAR spliced read aligner (18). Fragment counts were derived using HTSeq package (19). Differentially expressed genes were identified by a ranking based on adjusted $p$-values $\leq 0.005$ and a false discovery rate $\leq 0.1$ using the $\mathrm{R} /$ Bioconductor package edgeR (20). RNASeq data from the melanoma cell lines were uploaded to the European Nucleotide Archive (EMBLEBI). The corresponding accession numbers are as follows: JM1: ERS1949828 (SAMEA104324850); JM2: ERS1949829 (SAMEA104324851); JM3: ERS1949830 (SAMEA104324852); and JM4: ERS1949831 (SAMEA104324853). Samples correspond to JM1: MEL-XY1 cell line; JM2: MEL-XY2 cell line; JM3: MEL-XY3 cell line; and JM4: MEL-XX4 cell line.

\section{CCL2/MCP-1 and IL-10 Production by CSF-470}

To determine and quantify chemokines or cytokines produced by CSF-470 vaccine or by the composing cell lines, $5 \times 10^{5}$ cells were placed in 24-well plates in $1 \mathrm{~mL}$ of RPMI 1640 medium (Thermo Fisher Scientific, USA). After 6, 24, and 48 h incubation, cells were harvested and centrifuged at $1,500 \mathrm{rpm}$ for $5 \mathrm{~min}$. Supernatants were collected and stored at $-80^{\circ} \mathrm{C}$ until further analysis. Chemokine and cytokine levels were measured with ELISA kits (BD Biosciences, USA) following the manufacturer's instructions. Color intensity was measured at $450 \mathrm{~nm}$ in a BioRad plate reader. The standard curves and concentrations were calculated using GraphPad Prism 5.0 (USA).

\section{Obtention of Leukocytes, Peripheral Blood Mononuclear Cells (PBMCs), and Monocytes}

Peripheral blood was obtained from healthy donors (HDs) at the "Instituto Médico Alexander Fleming." This study was carried out in accordance with the recommendations of "Comite de Etica del Instituto Médico Especializado Alexander Fleming."

${ }^{1}$ http://hannonlab.cshl.edu/fastx_toolkit/.

${ }^{2}$ http://www.bioinformatics.babraham.ac.uk/projects/fastqc/. 
Blood samples from HD were obtained according to the Instituto Médico Alexander Fleming guidelines, at the Hemotherapy Service. Leukocytes were obtained after lysis of red blood cells with pH 7.3 ammonium-chloride buffer solution during $15 \mathrm{~min}$, washed with phosphate-buffered saline (PBS), incubated for another $10 \mathrm{~min}$, followed by a second wash with PBS. PBMCs were purified using a Ficoll density gradient (GE Healthcare, UK), and monocytes were isolated using an anti-CD14 ${ }^{+}$cell kit (Miltenyi, Germany) following the manufacturer's specifications.

\section{In Vitro Migration Assay}

Leukocyte chemotaxis was determined using HTS Transwell-24 units with $0.5 \mu \mathrm{m}$ pore polycarbonate membranes and $6.5 \mathrm{~mm}$ inserts (Costar, Corning, NY, USA). A total of $600 \mu \mathrm{L}$ of plain RPMI 1640 medium with the eventual addition of $5 \times 10^{5}$ CSF470 vaccine cells, $10 \mu \mathrm{g} / \mathrm{mL}$ GM-CSF (Laboratorio Pablo Cassará, Argentina), or 10,000 CFUs of BCG (Pasteur strain, Instituto Malbrán, Argentina) were added to the bottom wells. The top wells were loaded with $5 \times 10^{5}$ leukocytes or $1 \times 10^{6}$ PBMCs in $100 \mu \mathrm{L}$ RPMI and incubated for $6 \mathrm{~h}$ at $37^{\circ} \mathrm{C}$ in a $5 \% \mathrm{CO}_{2}$ incubator (Figure S1A in Supplementary Material). After removing the inserts, the cells in the bottom plate were harvested, washed, and incubated with antibodies for FACS analysis.

\section{FACS Analysis of Migrating Cells}

Leukocytes or PBMCs were incubated with PerCP anti-human $\mathrm{CD} 45 \mathrm{MAb}$ (clone 2D1) to distinguish between immune and CSF-470 vaccine cells. Figure S1B in Supplementary Material shows the gating strategy to analyze polymorphonuclear cells, lymphocytes, and monocytes. PE anti-CD3 (clone SK7) and APC anti-CD56 (clone B159) MAbs were used to select T and natural killer (NK) lymphocytes, respectively. From the T-cell population $\left(\mathrm{CD}^{+}\right)$, we also analyzed CD8 ${ }^{+}$cells with FITC anti-CD8 (clone RPA-T8). To characterize classical and nonclassical monocytes, we used FITC anti-CD16 (clone 3G8) and PE anti-CD14 (clone $\mathrm{M} 5 \mathrm{E} 2$ ). Isotype-matched irrelevant MAbs were used as negative controls. All MAbs were from BD Biosciences. Data acquisition was performed using FACSCanto II cytometer (BD Biosciences, USA), collecting total $\mathrm{CD}^{+} 5^{+}$events in the bottom well. Data analysis was performed with FlowJo software 10.0.7 (Tree Star Inc., USA).

\section{Phagocytosis Assay}

CSF-470 vaccine cells were stained with PKH67 (staining protocol as stated on the datasheet, Sigma, USA) and cultured with $\mathrm{CD} 14^{+}$purified monocytes with or without BCG and GM-CSF, for 4,24 , or $48 \mathrm{~h}$ at 37 or $4^{\circ} \mathrm{C}$, followed by $15 \mathrm{~min}$ room temperature incubation with PE-CD14 (clone M5E2). PKH67 incorporation by $\mathrm{CD} 14^{+}$cells was assessed on FACSCanto II Flow Cytometer (BD Biosciences). Data were analyzed using FlowJo software. Percentage of monocytes that has phagocytosed labeled material from CSF-470 vaccine was calculated as the proportion of $\mathrm{PKH}_{67}{ }^{+}$cells within the $\mathrm{CD} 14^{+}$population.

\section{PBMCs and Monocytes Stimulation}

A total of $5 \times 10^{5}$ PBMCs or purified monocytes were cultured in $1 \mathrm{~mL}$ RPMI 1640 medium supplemented with 10\% heat-inactivated fetal calf serum, $2 \mathrm{mM}$ glutamine, $100 \mathrm{U} / \mathrm{mL}$ penicillin, and $100 \mu \mathrm{g} / \mathrm{mL}$ streptomycin, alone or in the presence of $5 \times 10^{5} \mathrm{CSF}-470$ vaccine cells with or without adjuvants (160,000 CFUs of BCG plus $10 \mu \mathrm{g} / \mathrm{mL}$ GM-CSF). When indicated, $10 \mu \mathrm{g} / \mathrm{mL}$ anti IL-10 and anti TGF- $\beta$ inhibitory MAbs were added (anti IL-10 clone 23738, anti TGF- $\beta$ clone 1D11 or control isotypes mouse IgG2b clone 20116 and mouse IgG1 clone 11711; R\&D Systems, USA). After 6, 24, and $48 \mathrm{~h}$ incubation the medium was harvested and centrifuged at $1,500 \mathrm{rpm}$ for $5 \mathrm{~min}$. Supernatants were collected and stored at $-80^{\circ} \mathrm{C}$ until further analysis. TNF- $\alpha$, IL-1 $\beta$, IL-10, and IL-12 cytokines were measured in coculture supernatants using ELISA kits (BD Biosciences) as described.

\section{Statistical Analysis}

Statistical tests for migration assays and coculture experiments for cytokines measurements were done with Infostat 2011 software (21). Data were analyzed according to a randomized block design with repeated measures (time) using analysis of variance, considering time, treatments and their interactions as fixed factors, and HD as a random factor (blocks); $\alpha=0.05$. All models were tested for homoscedasticity and normality of residuals by visual assessment of plots. When homoscedasticity was not accomplished, models were fitted by the addition of the VarIdent, VarExp, or VarPower variance structure to the random part of the model (22). The best variance structure used in the fitted models was determined by comparison of Akaike's and Bayesian's Information Criteria. For monocytes and lymphocytes proportion comparison in migration assays, paired $T$-test was used (GraphPad Prism 5.0). A $p$ value $<0.05$ was considered to be statistically significant.

\section{RESULTS}

\section{CSF-470 Plus Adjuvants Attracted Leukocytes and PBMCs}

Since CSF-470 vaccine is injected intradermally with GM-CSF and BCG, we aimed to establish an in vitro coculture system to analyze the possible interaction between vaccine components and immune cells that may occur in vivo, with the limitation that no extracellular matrix, blood or lymphatic vessels were present. We first analyzed leukocyte migration. After $6 \mathrm{~h}$ incubation, the combination of CSF-470 plus adjuvants promoted stronger leukocyte migration than the individual components (Figure 1A, left). In decreasing order, CSF-470 and GM-CSF alone significantly attracted leukocytes, whereas BCG was not an attractor. We also analyzed which leukocyte sub populations were attracted. Granulocytes were the most attracted cells, followed by lymphocytes and monocytes, thus maintaining the same proportion as in peripheral blood (Figure 1A, left).

In order to explore the migration of potentially phagocytic immune cells, and due to the small percentage of monocytes in the total leukocyte sample, we decided to purify PBMC that led to an increase in the initial proportion of this cell subpopulation. When the migration assay was performed with PBMC instead of 


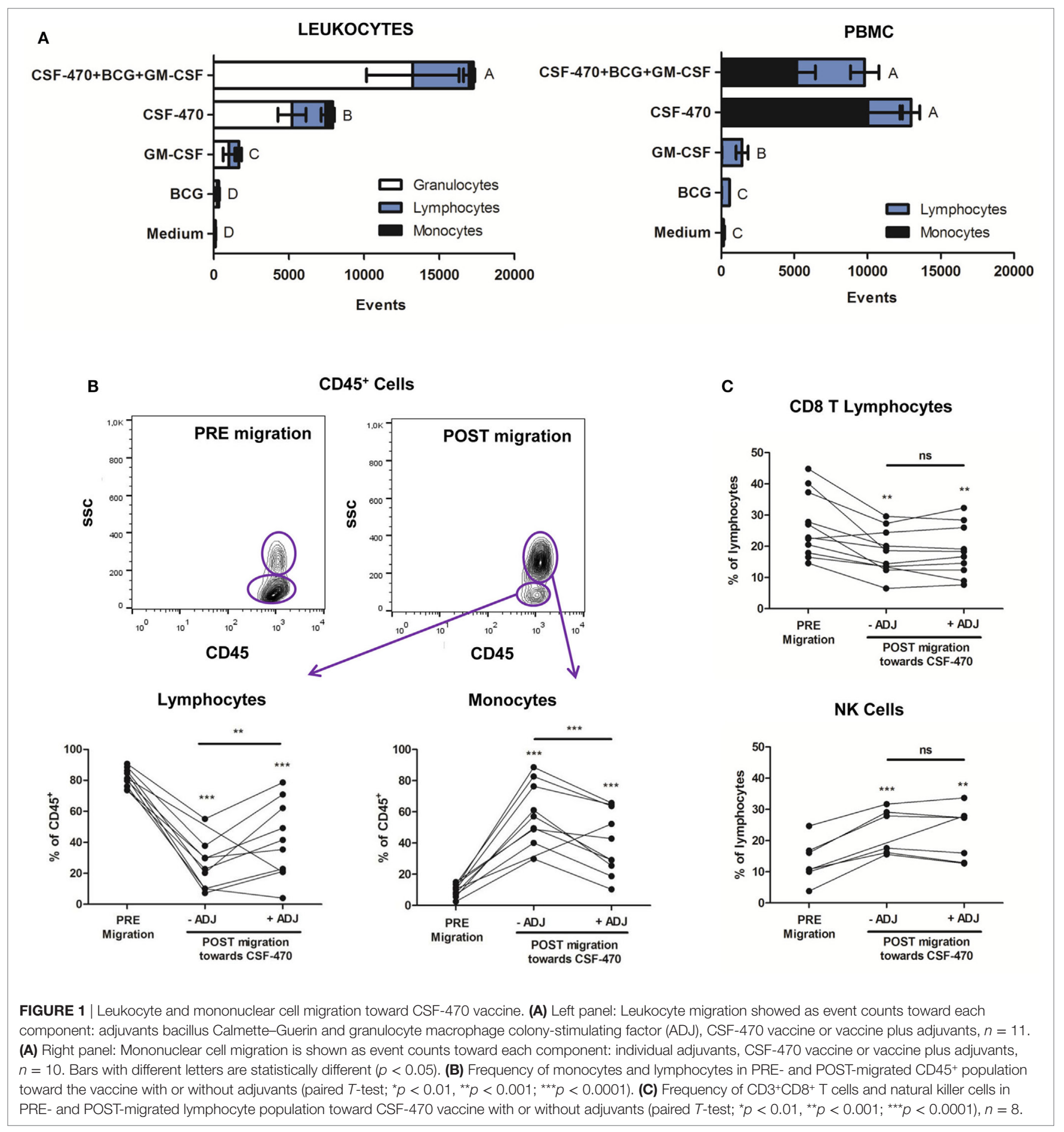

total leukocytes, we found that migration was mainly promoted by CSF-470 vaccine, while the presence of adjuvants did not modify such attraction (Figure 1A, right). After migration to CSF-470, monocytes were enriched and became the prevalent population $(9.8 \pm 3.9 \%$ PRE migration vs. $59.37 \pm 19.82 \%$ POST migration; $p<0.001$; Figure 1B, lower right panel). Lymphocytes were also attracted but reducing their proportion after migration $(81.6 \pm 5.95 \%$ PRE migration vs. $24.79 \pm 15.43 \%$ POST migration toward CSF-470; $p<0.001$; Figure 1B, lower left panel). When adjuvants were added, monocytes were also highly attracted $(9.8 \pm 3.9 \%$ PRE migration vs. $40.2 \pm 20.43 \%$ POST migration toward CSF-470 plus adjuvants; $p<0.001$; Figure 1B, lower right panel). Furthermore, migrated lymphocytes to CSF-470 vaccine or CSF-470 vaccine plus adjuvants showed an increase in the proportion of NK cells as compared to the pre-migration lymphocyte population, in detriment of $\mathrm{CD}^{+} \mathrm{CD}^{+} \mathrm{T}$ cells (Figure 1C). 
Phenotype assessment showed that monocyte CD14, CCR7, and MHC class II expressions were unchanged among treatments. Also, activation markers CD25 and CD69 remained low and constant in T lymphocytes and NK cells (data not shown). To summarize, cells from the innate immune system such as monocytes and NK cells appear to be preferentially attracted by CSF-470 vaccine.

\section{Classical Monocytes Are Attracted by CSF-470 Vaccine and Phagocytose- Irradiated Cells}

After PBMC migration, cells were harvested from the lower well and monocytes were characterized by CD14 and CD16 surface marker expression. CSF-470 vaccine, with or without adjuvants, preferentially attracted $\mathrm{CD} 14^{++} \mathrm{CD} 16^{-}$classical phagocytic monocytes (Figure 2A). To test the phagocytic capacity of monocytes, purified CD14+ cells were incubated with PKH67-labeled CSF470 vaccine cells, with or without adjuvants. After $4 \mathrm{~h}$ coculture, $21.0 \pm 1.4 \%$ of monocytes had captured cell-labeled material; this uptake increased to $70.7 \pm 0.9$ and $86.5 \pm 2.8 \%$ at 24 and $48 \mathrm{~h}$, respectively (Figure 2B). Phagocytosis was similar when adjuvants were present ( $4 \mathrm{~h}: 25.1 \pm 3.0 \% ; 24 \mathrm{~h}: 72.2 \pm 4.3 \%$; $48 \mathrm{~h}$ : $82.5 \pm 1.6 \%$ ).

\section{CSF-470 Cells Produce High Amount of Chemokines}

Monocytes and NK cells migrate to inflammatory sites in response to several chemokines $(23,24)$. RNAseq analysis allowed us to determine the expression profile of the four viable cells that compose the CSF-470 vaccine as shown in Figure 3A. MEL-XX4 cell line expresses high amounts of neutrophils chemoattractants CXCL1, CXCL2, and CXCL3. MEL-XX4, and to a lesser extent MEL-XY2, also express high amounts of CCL2/ MCP-1. To validate these results, we measured CCL2/MCP-1 protein secretion by irradiated CSF-470 cells after 6,24 , and $48 \mathrm{~h}$ of culture. It is worth mentioning that CCL2/MCP-1 mRNA expression by non-irradiated cells (RNAseq) and protein secretion to the conditioned medium from irradiated cells completely matched (Figure 3B). We evaluated PBMC chemoattraction to each cell line component of the vaccine separately. When tested individually, we observed that MEL-XX4 alone attracted more cells than the other three cell lines, although this tendency was not statistically significant (data not shown). Thus, additional chemoattractant factors, other than CCL2/MCP-1 may be responsible for monocyte and lymphocyte attraction.

\section{BCG Addition to CSF-470 Vaccine Triggers Monocyte Production of Pro-inflammatory Cytokines}

Monocyte activation is associated with the release of proinflammatory cytokines, mainly TNF- $\alpha$ and IL- $1 \beta$ (25). Thus, we measured the production of these cytokines in cocultures of PBMC and adjuvants BCG and GM-CSF and/or CSF-470. CSF-470 by itself was unable to induce secretion of either of these cytokines by PBMC. The low levels of IL-1 $\beta$ observed in PBMC-CSF-470 cocultures without adjuvants correspond to the production of this cytokine by CSF-470 vaccine cells (Figure S2 in Supplementary Material). Instead, BCG, but not GM-CSF, induced a high release of TNF- $\alpha$ and IL-1 $\beta$, leading to cytokine accumulation for $48 \mathrm{~h}$ (Figure 4). At the first $6 \mathrm{~h}$, GM-CSF increased TNF- $\alpha$ release induced by BCG, but in the following time, it did not contribute to its production. On the other hand, GM-CSF had no impact on IL- $1 \beta$ release. The presence of the vaccine cells partially inhibited cytokines production stimulated by BCG, but still significant levels of TNF- $\alpha$ and IL- $1 \beta$ could be detected. Thus, BCG was required to induce local inflammation in the presence of CSF-470 vaccine cells (Figure 4). When cocultures were performed using purified $\mathrm{CD}_{14}{ }^{+}$monocytes or peripheral blood lymphocytes from PBMCs, monocytes were the leading producers of TNF- $\alpha$ and IL- $1 \beta$ at least during the first $48 \mathrm{~h}$ (data not shown).

In order to quantify the BCG induction of TNF- $\alpha$ release by PBMC and its inhibition by CSF- 470 cells, we performed concentration curves. Results are depicted in Figure S3 in Supplementary Material. TNF- $\alpha$ release showed a BCG dosedependent pattern, characterized by the highest release at $24 \mathrm{~h}$ with 500,000 CFUs of BCG, the highest amount tested. Opposite to that, increasing amounts of CSF-470 cells decreased TNF- $\alpha$ release in a dose-dependent way. IL-12 could not be detected in these cocultures (data not shown).

\section{CSF-470 Produces High Amounts of Immune Suppressive Molecules}

Bacillus Calmette-Guerin is directly recognized by TLR-2 and TLR-4 in monocytes and actively stimulates TNF- $\alpha$ and IL- $1 \beta$ production (26). In our setting, BCG alone or with GM-CSF efficiently induced both inflammatory cytokines; however, the presence of CSF-470 vaccine significantly reduced pro-inflammatory cytokines secretion. To investigate the mechanisms that could explain that phenomenon, we evaluated by RNAseq the expression of several immune suppressive factors commonly produced by tumor cells.

Analysis of the four cell lines comprising CSF-470 vaccine showed abundant expression of SPARC, TGF- $\beta$, IL-10, and galectins 1, 3, 8, and 9 mRNAs (Figure 5A). Of note, MEL-XY1 cell line was the only IL-10 producer as demonstrated both at the mRNA and protein levels (Figures 5A,B). Furthermore, the high levels of IL-10 cytokine detected in supernatants of PBMC cocultures with CSF-470 plus adjuvants came mostly from CSF470 vaccine cells (Figure 5C). However, cocultures of PBMC with the individual cell lines comprising the CSF-470 vaccine showed that inhibition of TNF- $\alpha$ release mediated by MEL-XY1 was similar to the inhibitory effect mediated by non-expressing IL-10 cell lines (Figure 5D). Therefore, other immunosuppressive factors are probably contributing to the hampered TNF- $\alpha$ release by $\mathrm{PBMC}$ exposed to the vaccine.

\section{IL-10 and TGF- $\beta$ Are Responsible for CSF-470 Vaccine Immunosuppression}

Finally, in order to demonstrate the immune suppressive role of IL-10 and TGF- $\beta$ produced by CSF-470 vaccine, we measured 

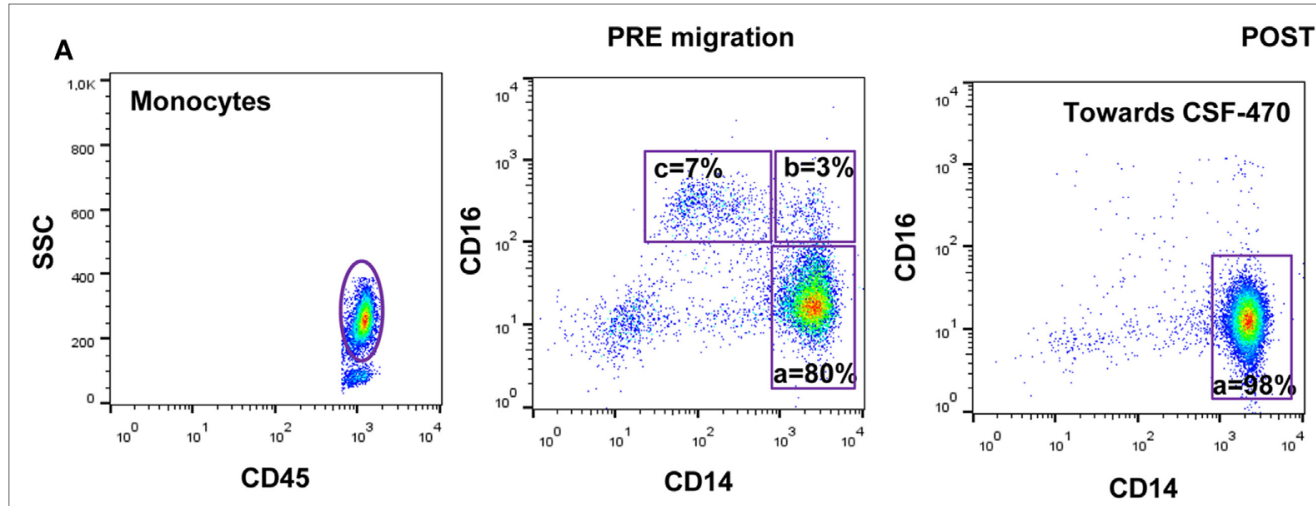

POST migration
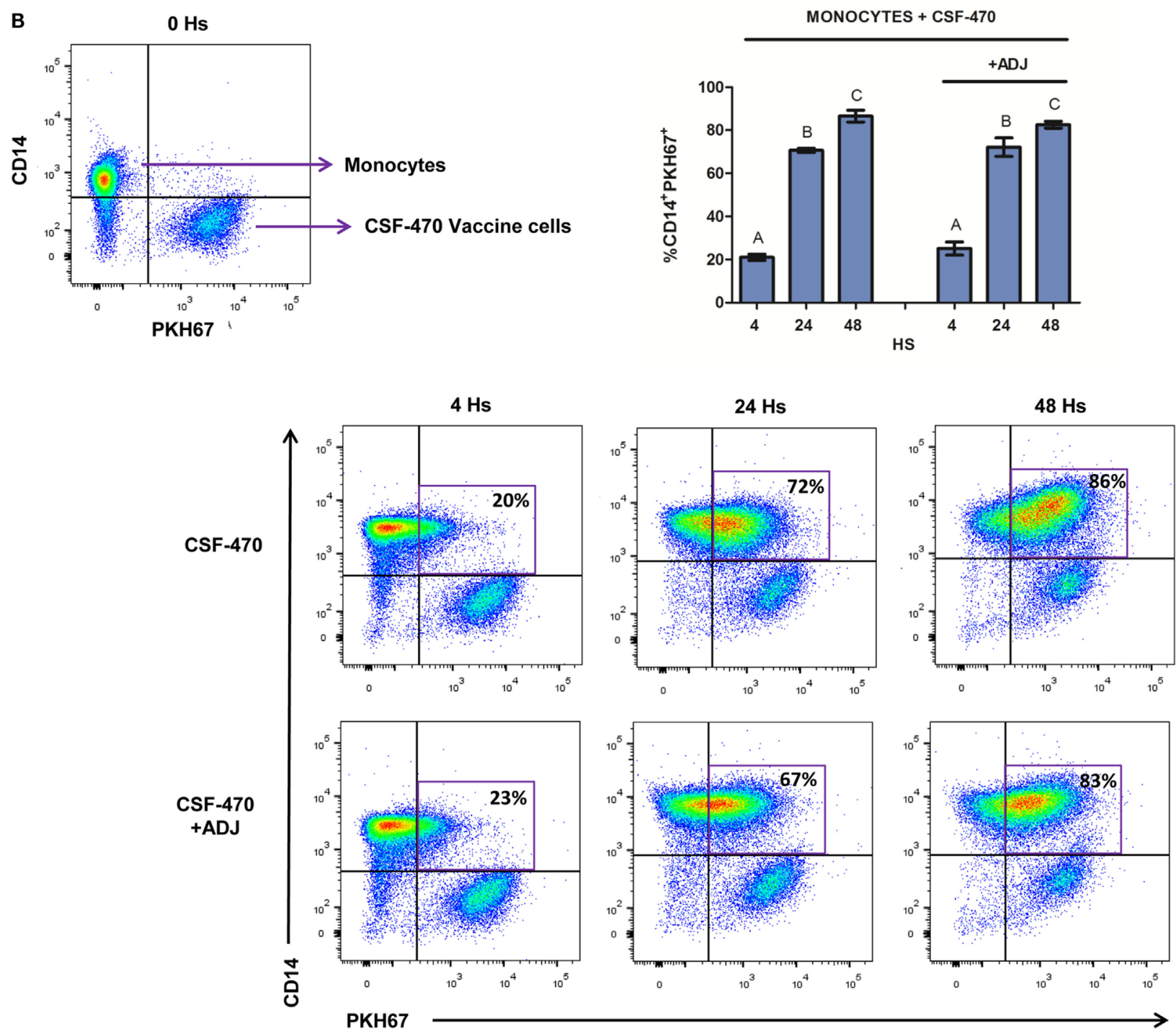

FIGURE 2 | Classical monocytes migration and phagocytosis of irradiated cells. (A) Proportion of classical $\left(a=C D 14^{++} C D 16^{-}\right)$, intermediate $\left(b=C D 14^{++} C D 16^{+}\right)$, and nonclassical monocytes $\left(\mathrm{C}=\mathrm{CD} 14^{+} \mathrm{CD}_{16}{ }^{++}\right)$PRE and POST migrations toward CSF-470 vaccine, with or without adjuvants bacillus Calmette-Guerin and granulocyte macrophage colony-stimulating factor (ADJ). One representative experiment is shown. (B) Phagocytosis of CSF-470 vaccine cells at 4, 24, and 48 h. Selected gates represent the percentage of monocytes that have phagocytose-labeled material from CSF-470 vaccine. Bars represent the percentage of monocytes from healthy donor $(n=3)$ that uptake irradiated CSF-470 cells (double staining CD14+ $\mathrm{PKH} 67^{+}$) at 4,24 , and $48 \mathrm{~h}$. Bars with different letter are statistically different $(p<0.05)$. To illustrate, representative dot plots from one experiment are depicted. 

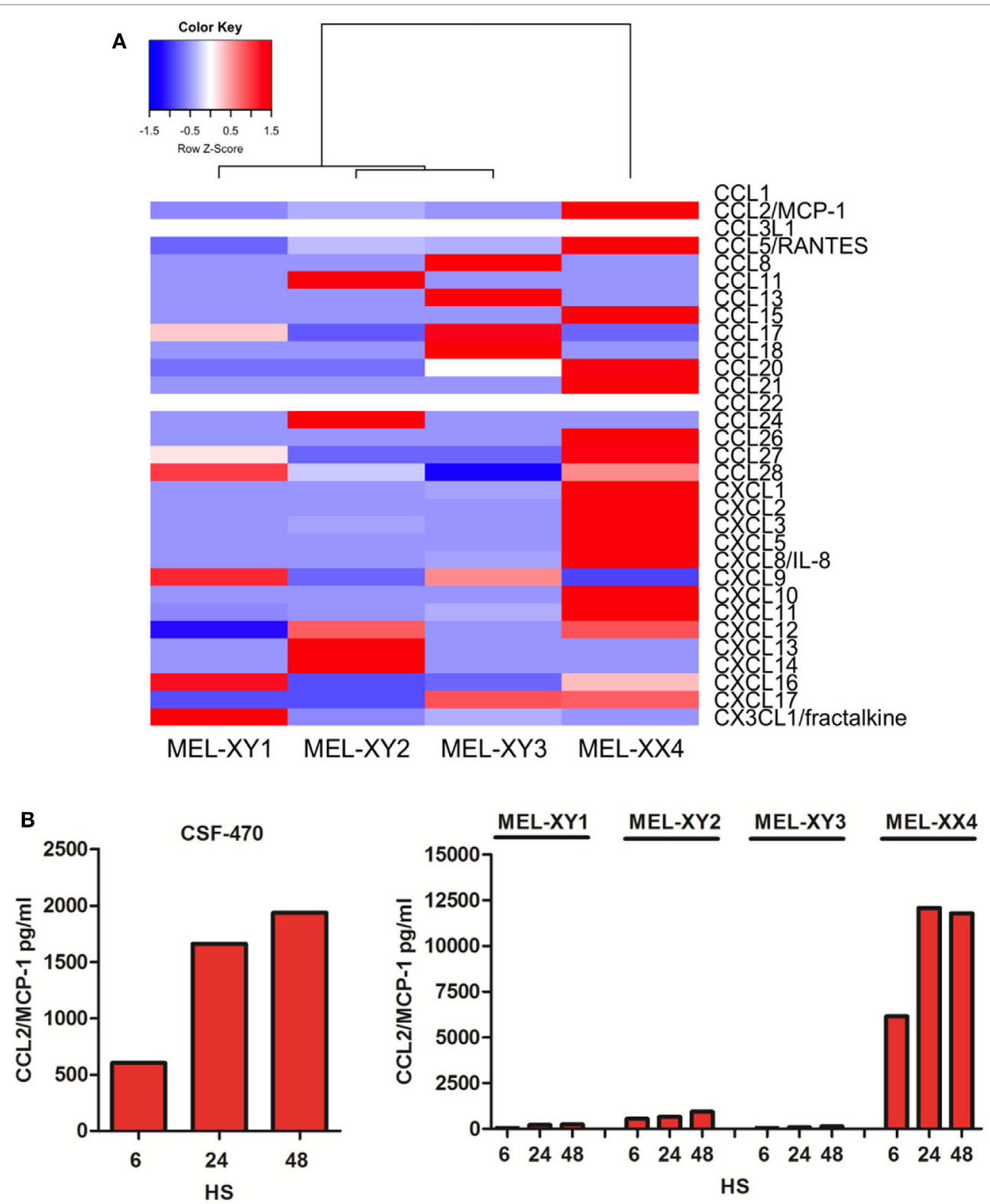

FIGURE 3 | Chemokine expression profile of cutaneous melanoma cell lines components of CSF-470 vaccine. (A) Chemokines expression by non-irradiated MEL-XY1, MEL-XY2, MEL-XY3, and MEL-XX4 cells by RNAseq. Transcript abundance for each cell line is shown as fragments per kilobase of exon per million fragments mapped. (B) CCL2/MCP-1 protein expression at 6, 24, and $48 \mathrm{~h}$ supernatants from CSF-470 vaccine cells and each irradiated cell line.

TNF- $\alpha$ released by PBMC cocultures with CSF-470 plus adjuvants, in the presence of blocking MAbs against IL-10 and/or TGF- $\beta$. Figure 6 shows that blocking IL-10 and TGF- $\beta$ increased TNF- $\alpha$ secretion by PBMC after $24 \mathrm{~h}$ coculture with CSF-470 vaccine plus adjuvants, suggesting that these cytokines strongly hampered TNF- $\alpha$ secretion induced by BCG addition.

\section{DISCUSSION}

The current state of the art proposes that for a cancer vaccine to be useful in the development of an immunological response, Ag-presenting cells must capture Ags and process them, activate and mature, traffic to the lymph nodes (LNs), and prime naive T cells. Alternatively, Ags could be captured directly at the LN level. Immunological activation would translate into a clinical response by trafficking of $\mathrm{T}$ cells into tumors, activation of T-cell effector functions after engagement of tumor $\mathrm{Ag}$, and consequent lysis of tumor cells.

In the previously described Phase II clinical trial, CSF-470 vaccine plus BCG and GM-CSF as adjuvants was administrated at frequent intervals for a total of 13 vaccinations over a twoyear period. Besides challenging the immune system with a broad repertoire of CM Ags (27) and non-identical HLAs, the treatment strategy included the use of BCG in every vaccination 

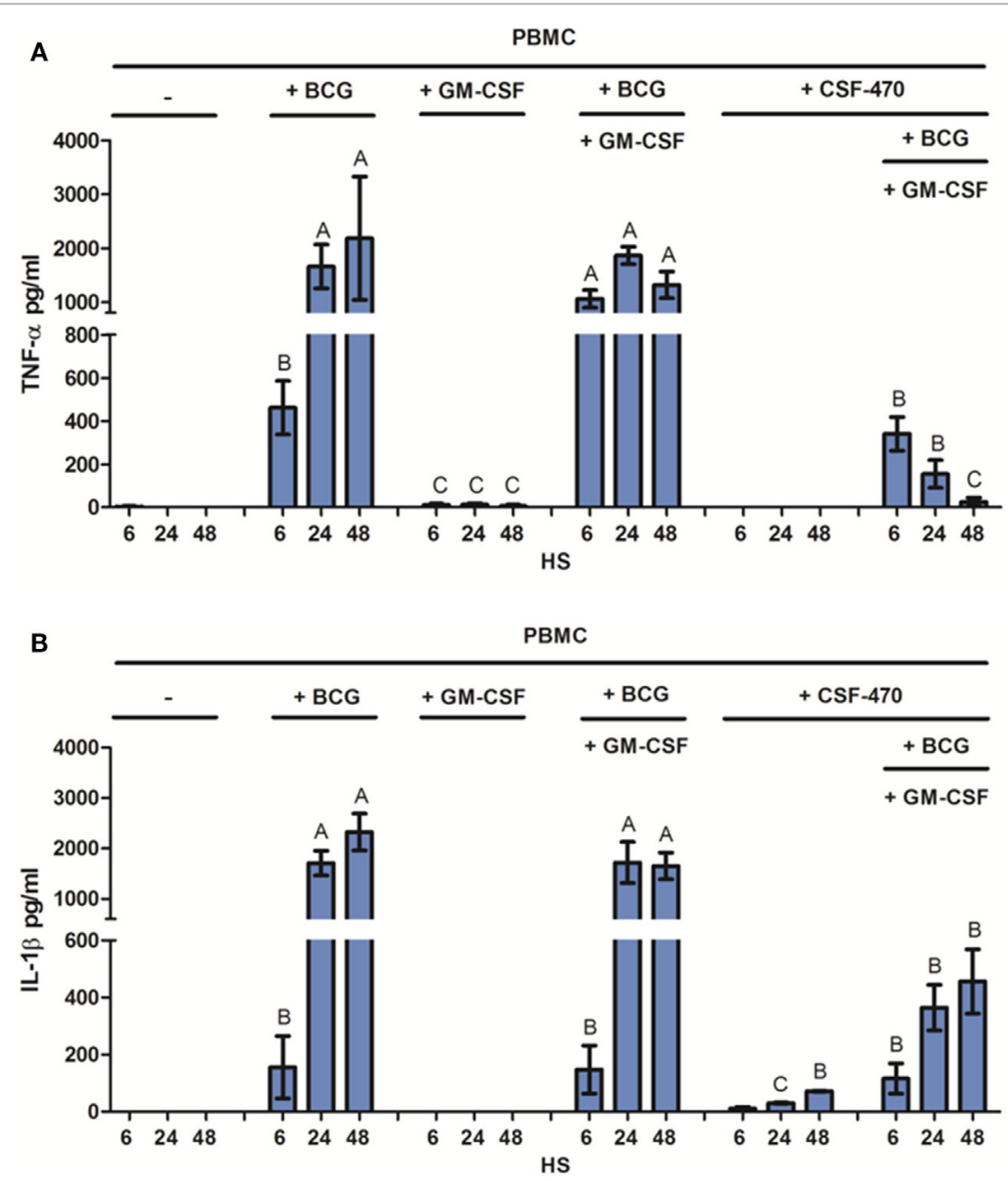

FIGURE 4 | Pro-inflammatory cytokines released by peripheral blood mononuclear cell (PBMC) in CSF-470 cocultures with or without adjuvants, after 6 , 24, and $48 \mathrm{~h}$. (A) TNF- $\alpha$ released by PBMC, $n=6$. (B) IL-1 $\beta$ released by PBMC, $n=3$. Bars with different letters are statistically different $(p<0.05)$.

to induce local inflammation, polarize immune cells toward a $\mathrm{TH}_{1}$ response and activate NK cell cytotoxicity and memorylike response $(28,29)$. Moreover, GM-CSF was injected with every vaccination during 4 days presumably contributing to differentiate monocytes into dendritic cells (DCs) as shown in vitro (30). In that clinical trial, immune monitoring demonstrated significant increases in peripheral $\mathrm{T}$ cells reactive against melanoma Ags, peripheral NK cells frequency, and a specific antibody response. However, the events that take place at the vaccination site remain speculative since the in situ reaction starts within hours, and it lasts for weeks. Another hindrance for that analysis is that sequential biopsies of the injection site are difficult to obtain; besides, the inflammatory changes do vary with subsequent vaccinations. In the present work, using an in vitro model similar to that used to evaluate migration to a DC vaccine (31), we analyzed the first steps of the interaction among CSF-470, BCG, GM-CSF, and leukocytes from HD. We established that leukocytes migration was promoted within hours, with CSF-470 being the highest attractor. Innate immune cells were mostly attracted, and among them, neutrophils, probably because CXCL1 and CXCL2 chemokines, which mediate neutrophils recruitment $(32,33)$, were highly expressed by MEL-XX4 cells. When we focused on PBMC, monocyte was the main migrating mononuclear cells. Since it has been reported that monocytes role on vaccination depends on their subtype (34-36), we determined that the attracted monocytes mainly belonged to the $\mathrm{CD} 14^{++} \mathrm{CD} 16^{-}$classic phagocytic type. This subtype represents approximately $85 \%$ of the $\mathrm{CD} 14^{+}$population and expresses CD62L, CCR2, CLEC4D, CLEC5A, IL13Ra1, CXCR1, and CXCR2 (25). CCL2/MCP-1 regulates the migration and infiltration of monocytes, memory $\mathrm{T}$ lymphocytes, and NK cells (37). Considering that high mRNA and protein levels of CCL2/MCP-1, the ligand of the CCR2, were found in CSF-470, this chemokine may partially contribute to monocytes and NK migration, at least within the first 48 h; however, it should be confirmed by blocking CCL2/ MCP-1 in the migration assay.

It has been reported by others (38) that CCL2/MCP-1 exogenously administered or produced locally at inflammatory sites, could drain into regional LNs, where it binds to high 


\begin{tabular}{|l|c|c|c|c|}
\hline & MEL-XY1 & MEL-XY2 & MEL-XY3 & MEL-XX4 \\
\hline IL-10 & 487 & 0 & 16 & 1 \\
\hline TGF- 1 $_{1}$ & 1905 & 8392 & 1106 & 4558 \\
\hline SPARC & 267 & 234 & 158 & 110 \\
\hline LGALS1 & 7803 & 15445 & 11315 & 8746 \\
\hline LGALS2 & 0 & 2 & 0 & 3 \\
\hline LGALS3 & 4758 & 1676 & 7855 & 1880 \\
\hline LGALS4 & 2 & 4 & 1 & 1 \\
\hline LGALS8 & 679 & 1138 & 503 & 1695 \\
\hline LGALS9 & 5 & 16 & 26 & 434 \\
\hline LGALS12 & 0 & 0 & 0 & 2 \\
\hline LGALS17A & 0 & 0 & 0 & 3 \\
\hline
\end{tabular}
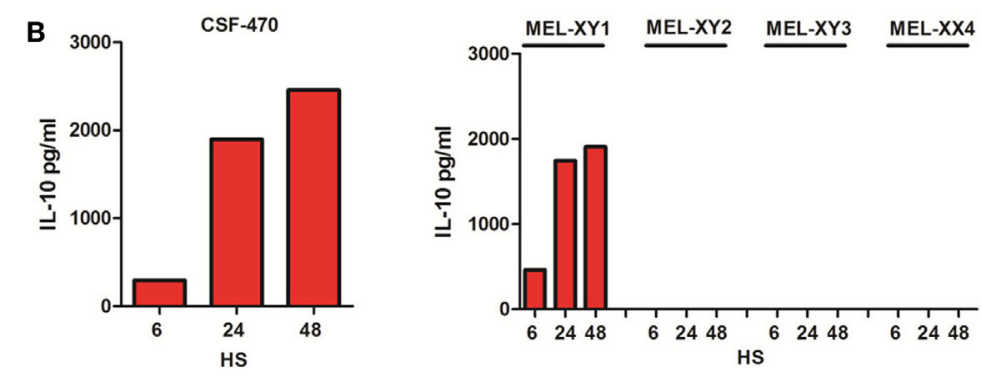

PBMC

C
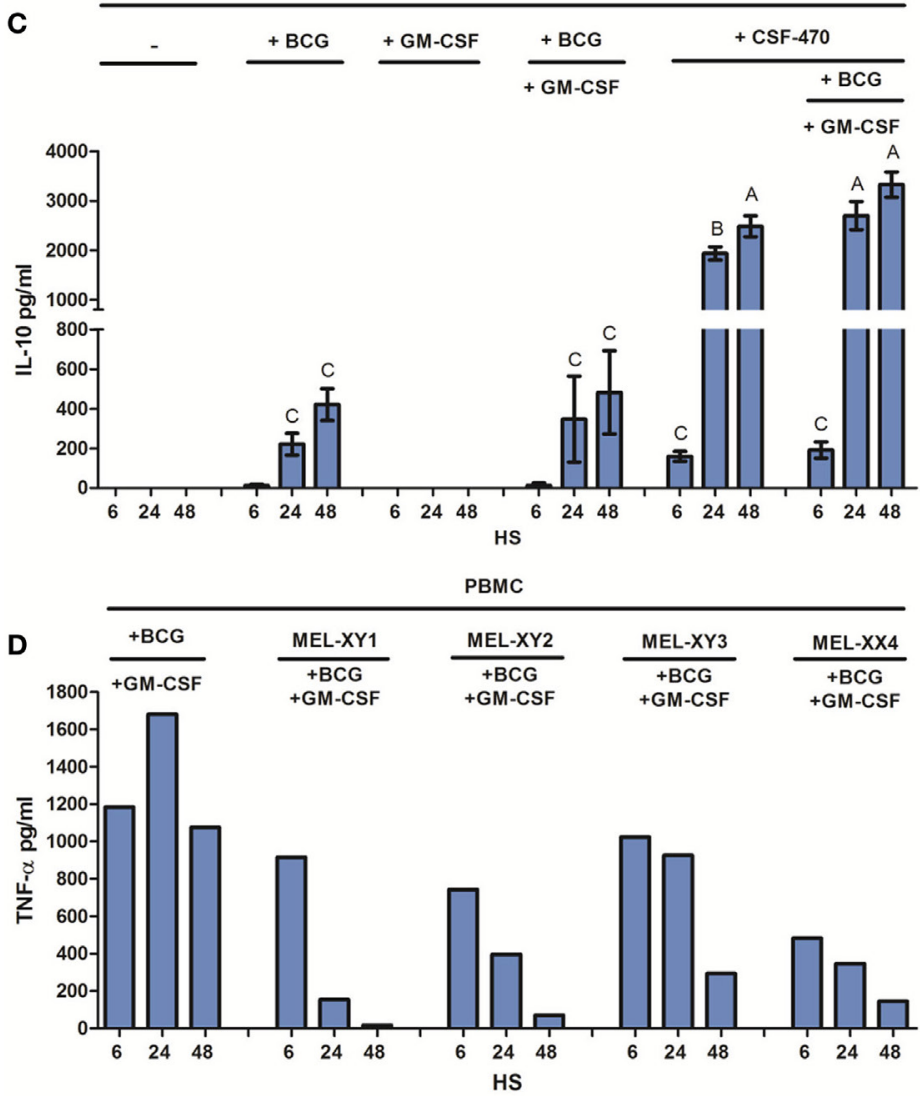

FIGURE 5 | Anti-inflammatory cytokine production by CSF-470 vaccine. (A) IL-10, TGF- $\beta$, SPARC, and galectin expressions by RNAseq from MEL-XY1, MEL-XY2, MEL-XY3, and MEL-XX4 cell lines. (B) IL-10 detected in conditioned media of CSF-470 or each irradiated cell lines after 6, 24, and 48 h. (C) IL-10 detected in supernatants of peripheral blood mononuclear cell (PBMC) cocultures with CSF-470 with or without adjuvants. Bars with different letters are statistically different $(p<0.05)$. (D) TNF- $\alpha$ release by PBMC exposed to each irradiated cell line plus adjuvants bacillus Calmette-Guerin and granulocyte macrophage colony-stimulating factor. 


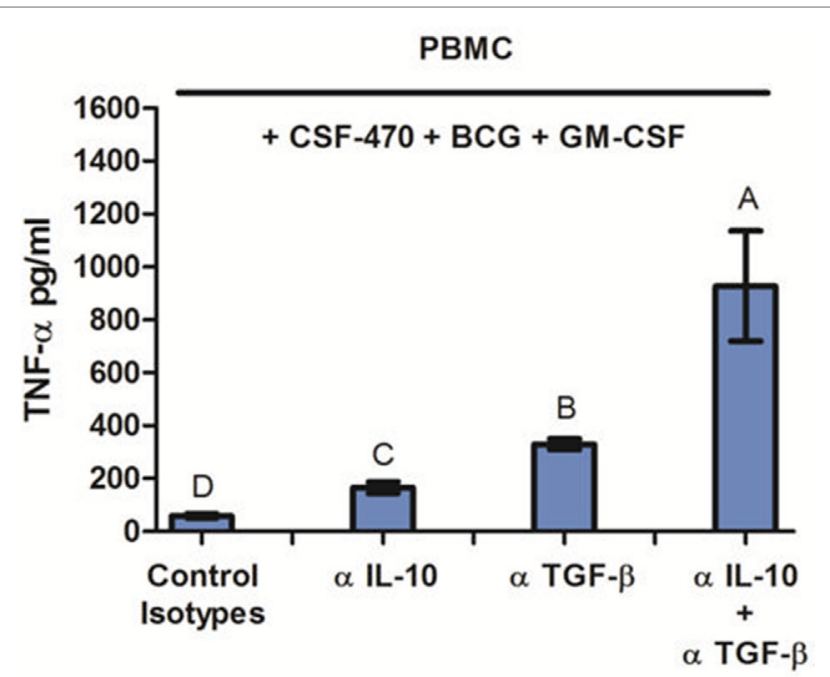

FIGURE 6 | TNF- $\alpha$ release by peripheral blood mononuclear cell coculture with CSF-470 plus adjuvants at $24 \mathrm{~h}$ in the presence of blocking antibodies against IL-10 and/or TGF- $\beta$. Bars with different letters are statistically different $(p<0.05), n=3$.

endothelial venules and triggers circulating monocyte binding and diapedeses. In vaccinated patients, assuming that not every CSF-470 Ags are phagocytosed in situ and that in experimental models only about $2 \%$ of Ag-loaded DC reach the draining LN $(39,40)$, such blood-derived monocytes could phagocytose tumor Ags directly drained into LNs and further trigger naive lymphocytes education. However, our in vitro assay is quite simple and does not allow us to understand further events that may take place at longer times of interaction. It is probable that monocytes have multiple roles in this setting, besides cytokine production, as described by Italiani et al. (41). Either tissue monocytes or blood monocytes recruited in response to inflammatory stimuli have been shown to give rise to the inflammatory monocyte-derived macrophages, while some of them do not differentiate into macrophages and remain monocyte-like cells. They can take up Ag and migrate to the draining LNs (tissue monocytes); these are the Ag-uptaking and -presenting cells of the tissue. Although we have evidenced monocyte phagocytosis of tumor irradiated cells in this setting, we have not evaluated T-cell priming. Given that up to $48 \mathrm{~h}$ of interaction we did not observe upregulation of CCR7 (data not shown), these $\mathrm{CD} 14^{+}$monocytes might still not be able to differentiate to Ag-presenting cells and migrate to LNs to allow canonical T-cell priming. However, events that would take longer to occur and/or be induced by monocyte interaction with other components of the inoculation site such as other immune cells, stroma, and vascular cells, could not be evaluated in our in vitro assays. It is hard to ascertain, which is the origin of the Ag-presenting cells in the dermis after vaccination. The vaccination nodules are located well below the epidermis (42), so it would not appear probable that epidermal residing Langerhans cells are directly involved in the first Ag-presenting process. However, their role after repeated vaccinations may not be discarded, since it has been demonstrated that under inflammatory conditions, Langerhans cells may induce a shift from skin resident, T regulatory memory lymphocytes to effector memory lymphocytes (43).

Even in the case of BCG used as an inflammatory stimulant for noninvasive bladder carcinoma, where research has been extensively pursued, the role of monocyte/macrophages in BCG response has been suggested but not confirmed in vivo, evidencing the complexity of appropriate models to study these multiple interactions. However, an increase in IFN- $\gamma$ release by lymphocytes of patients treated with an antitumoral vaccine was observed when BCG was used as an adjuvant (44).

Bacillus Calmette-Guerin dramatically induced TNF- $\alpha$ and IL- $1 \beta$ release by monocytes at high nM levels, leading to cytokines accumulation peaking at $24 \mathrm{~h}$ for TNF- $\alpha$ and at least $48 \mathrm{~h}$ for IL-1 $\beta$. As to the mechanism by which BCG acts on monocytes, it is well known that it interacts with multiple receptors such as TLR-2, TLR-4, and NLRs, stimulating innate immunity and leading to specific adaptive immunity (45). Among the benefits of released TNF- $\alpha$ on vaccination, it may be quoted that attained levels may induce production of endothelial leukocyte adhesion molecule 1 by endothelial cells (46) and therefore enhance leukocyte entry into the vaccination site. Other positive effects of TNF- $\alpha$ and IL- $1 \beta$ release stems from the fact that prior work from our laboratory demonstrated that both cytokines are necessary to restore the mixed lymphocyte reaction ability of DCs after phagocytosis of tumor irradiated cells (47). On the other hand, if not counterbalanced, high TNF- $\alpha$ release by monocyte activation could be detrimental for the long range activation of the immune system. Although its role in fibrotic diseases is still controversial, the TNF- $\alpha$ pro-inflammatory properties in the initial phases of fibrosis development have been deeply characterized in experimental models (48). Therefore, an enhanced granulomatous reaction would encapsulate the vaccination site and consequently, hinder the access of Ag-presenting cells to the antigenic focus and the exit of particulate material to draining LNs. CSF-470 by itself did not induce cytokines release by monocytes, and it diminished about 20 -fold the BCG activity on such release.

Vaccine cell lines expressed IL-10, galectins 1, 3, and 8, SPARC, and TGF- $\beta$, which induce immune suppression in a variety of ways (49-54). In fact, IL-10, released only by MEL-XY1 cell line, is considered the most important cytokine preventing inflammation-mediated tissue damage (49). Furthermore, the immunosuppressive effect of CSF-470 on TNF- $\alpha$ release by monocytes could be partially reversed by blocking TGF- $\beta$ and IL-10, suggesting an important role for these cytokines, at least during the first $48 \mathrm{~h}$.

In the analyses here performed, GM-CSF appeared to play a minor role, and we suggest this is so because this cytokine would act at later stages of vaccination. On one hand, it would enhance endothelial proliferation and subsequent PBMC efflux to the injection site. In fact, a substantial erythema appeared at the injection site in vaccinated patients when GM-CSF was added, which lasted for 2-4 days and then subsided (13). The analysis of this possible effect of GM-CSF could not be performed since no endothelial cells were added to our system. On the other hand, 
GM-CSF would drive monocyte differentiation into DCs, a late effect that was not analyzed in our system.

Thus, as a final result, a balance between pro-inflammatory and anti-inflammatory chemokines and cytokines might be established at the vaccination site. It could be assumed that, if given alone, CSF-470 would act as a sink for PBMC, attracting them by expressing a variety of chemokines and, through immunosuppressive factors, blocking the release of inflammatory cytokines by PBMC. BCG enters this equation by partially reversing such inhibition, and it is, therefore, an essential player. It is hard to link the early in vitro events determined in this paper with the immune stimulation obtained in patients after several vaccinations (13); nevertheless, they offer a glimpse of the events taking place after the first vaccination. Establishing experimental systems that allow analyzing cell interactions in a longer time frame is highly desirable.

\section{ETHICS STATEMENT}

This study was carried out in accordance with the recommendations of "Comite de Etica del Instituto Medico Especializado Alexander Fleming." Blood samples from healthy donors were obtained according to the Instituto Medico Alexander Fleming guidelines, at the Hemotherapy Service.

\section{AUTHOR CONTRIBUTIONS}

MP, JM, and EL collected and assembled the data, analyzed and interpreted the data, and wrote the manuscript. MB analyzed

\section{REFERENCES}

1. Clemente CG, Mihm MC, Bufalino R, Zurrida S, Collini P, Cascinelli N. Prognostic value of tumor infiltrating lymphocytes in the vertical growth phase of primary cutaneous melanoma. Cancer (1996) 77:1303-10. doi:10.1002/ (SICI)1097-0142(19960401)77:7<1303:AID-CNCR12>3.0.CO;2-5

2. Hodi FS, Chesney J, Pavlick AC, Robert C, Grossmann KF, McDermott DF, et al. Combined nivolumab and ipilimumab versus ipilimumab alone in patients with advanced melanoma: 2-year overall survival outcomes in a multicentre, randomised, controlled, phase 2 trial. Lancet Oncol (2016) 17:1558-68. doi:10.1016/S1470-2045(16)30366-7

3. Larkin J, Chiarion-Sileni V, Gonzalez R, Grob JJ, Cowey CL, Lao CD, et al. Combined nivolumab and ipilimumab or monotherapy in untreated melanoma. N Engl J Med (2015) 373:23-34. doi:10.1056/NEJMoa1504030

4. Topalian SL, Sznol M, McDermott DF, Kluger HM, Carvajal RD, Sharfman WH, et al. Survival, durable tumor remission, and long-term safety in patients with advanced melanoma receiving nivolumab. J Clin Oncol (2014) 32:1020-30. doi:10.1200/JCO.2013.53.0105

5. Rosenberg SA, Yang JC, Restifo NP. Cancer immunotherapy: moving beyond current vaccines. Nat Med (2004) 10:909-15. doi:10.1038/nm1100

6. Terando AM, Faries MB, Morton DL. Vaccine therapy for melanoma: current status and future directions. Vaccine (2007) 25(Suppl 2):B4-16. doi:10.1016/j. vaccine.2007.06.033

7. Slingluff CL, Petroni GR, Olson W, Czarkowski A, Grosh WW, Smolkin M, et al. Helper T-cell responses and clinical activity of a melanoma vaccine with multiple peptides from MAGE and melanocytic differentiation antigens. J Clin Oncol (2008) 26:4973-80. doi:10.1200/JCO.2008.17.3161 and interpreted the data and wrote the manuscript. EJ analyzed and interpreted the data and wrote the manuscript. PB collected and assembled the data. EE collected and assembled the data and analyzed and interpreted the data.

\section{ACKNOWLEDGMENTS}

We thank the Departments of Hemotherapy, Library, and Pharmacy from Instituto Médico Especializado Alexander Fleming for their help in this study. The authors thank Dr. Gerardo Cueto (FCEyN, University of Buenos Aires) for statistical assistance.

\section{FUNDING}

This work was supported by grants from CONICET, Agencia Nacional de Promoción Científica y Tecnológica (ANPCyT), Instituto Nacional del Cáncer - Ministerio de Salud de la Nación Argentina (INC-MSal), Fundación Sales, Fundación Cáncer, Fundación Pedro F. Mosoteguy, Argentina. MB, JM, and EL are the members of CONICET. MP and EJ are the fellows from CONICET.

\section{SUPPLEMENTARY MATERIAL}

The Supplementary Material for this article can be found online at http://www.frontiersin.org/article/10.3389/fimmu.2017.01342/ full\#supplementary-material.

8. Chin L, Garraway LA, Fisher DE. Malignant melanoma: genetics and therapeutics in the genomic era. Genes Dev (2006) 20:2149-82. doi:10.1101/ gad.1437206

9. Dutton-Regester K, Hayward NK. Reviewing the somatic genetics of melanoma: from current to future analytical approaches. Pigment Cell Melanoma Res (2012) 25:144-54. doi:10.1111/j.1755-148X.2012.00975.x

10. Barrio MM, de Motta PT, Kaplan J, von Euw EM, Bravo AI, Chacón RD, et al. A phase I study of an allogeneic cell vaccine (VACCIMEL) with GM-CSF in melanoma patients. J Immunother (2006) 29:444-54. doi:10.1097/01. cji.0000208258.79005.5f

11. von Euw EM, Barrio MM, Furman D, Bianchini M, Levy EM, Yee C, et al. Monocyte-derived dendritic cells loaded with a mixture of apoptotic/ necrotic melanoma cells efficiently cross-present gp 100 and MART-1 antigens to specific CD8(+) T lymphocytes. J Transl Med (2007) 5:19. doi:10.1186/ 1479-5876-5-19

12. von Euw EM, Barrio MM, Furman D, Levy EM, Bianchini M, Peguillet I, et al. A phase I clinical study of vaccination of melanoma patients with dendritic cells loaded with allogeneic apoptotic/necrotic melanoma cells. Analysis of toxicity and immune response to the vaccine and of IL-10 -1082 promoter genotype as predictor of disease. J Transl Med (2008) 6:6. doi:10.1186/ 1479-5876-6-6

13. Mordoh J, Pampena MB, Aris M, Blanco PA, Lombardo M, von Euw EM, et al. Phase II study of adjuvant immunotherapy with the CSF-470 vaccine plus bacillus Calmette-Guerin plus recombinant human granulocyte macrophage-colony stimulating factor vs medium-dose interferon alpha $2 \mathrm{~B}$ in stages IIB, IIC, and III cutaneous melanoma patie. Front Immunol (2017) 8:625. doi:10.3389/fimmu.2017.00625 
14. Redelman-Sidi G, Glickman MS, Bochner BH. The mechanism of action of BCG therapy for bladder cancer: a current perspective. Nat Rev Urol (2014) 11:153-62. doi:10.1038/nrurol.2014.15

15. Sloot $S$, Rashid OM, Zager JS. Intralesional therapy for metastatic melanoma. Expert Opin Pharmacother (2014) 15:2629-39. doi:10.1517/1465656 6.2014.967682

16. Ushach I, Zlotnik A. Biological role of granulocyte macrophage colonystimulating factor (GM-CSF) and macrophage colony-stimulating factor (M-CSF) on cells of the myeloid lineage. J Leukoc Biol (2016) 100:481-9. doi:10.1189/jlb.3RU0316-144R

17. Van De Laar L, Coffer PJ, Woltman AM. Regulation of dendritic cell development by GM-CSF: molecular control and implications for immune homeostasis and therapy. Blood (2012) 119:3383-93. doi:10.1182/blood-201111-370130

18. Dobin A, Davis CA, Schlesinger F, Drenkow J, Zaleski C, Jha S, et al. STAR: ultrafast universal RNA -seq aligner. Bioinformatics (2013) 29:15-21. doi:10.1093/bioinformatics/bts635

19. Anders S, Pyl PT, Huber W. HTSeq-A Python framework to work with high-throughput sequencing data. Bioinformatics (2015) 31:166-9. doi:10.1093/bioinformatics/btu638

20. Robinson MD, McCarthy DJ, Smyth GK. edgeR: a bioconductor package for differential expression analysis of digital gene expression data. Bioinformatics (2009) 26:139-40. doi:10.1093/bioinformatics/btp616

21. Di Rienzo JA, Casanoves F, Balzarini MG, Gonzalez L, Tablada M, Robledo CW. Infostat Version 2011. Argentina: Grupo InfoStat, Facultad de Ciencias Agropecuarias, Universidad Nacional de Córdoba (2011). Vol. 8. p. 195-9.

22. Pinheiro JC, Bates DM, N. Springer, New York. Mixed-Effects Models in S and S-PLUS. New York: Springer-Verlag (2000).

23. Imhof BA, Aurrand-Lions M. Adhesion mechanisms regulating the migration of monocytes. Nat Rev Immunol (2004) 4:432-44. doi:10.1038/ nril 375

24. Bernardini G, Antonangeli F, Bonanni V, Santoni A. Dysregulation of chemokine/chemokine receptor axes and NK cell tissue localization during diseases. Front Immunol (2016) 7:402. doi:10.3389/fimmu.2016.00402

25. Wong KL, Yeap WH, Tai JJY, Ong SM, Dang TM, Wong SC. The three human monocyte subsets: implications for health and disease. Immunol Res (2012) 53:41-57. doi:10.1007/s12026-012-8297-3

26. Tsuji S, Matsumoto M, Takeuchi O, Akira S, Azuma I, Hayashi A, et al. Maturation of human dendritic cells by cell wall skeleton of Mycobacterium bovis bacillus Calmette-Guérin: involvement of toll-like receptors. Infect Immun (2000) 68:6883-90. doi:10.1128/IAI.68.12.6883-6890.2000

27. Aris M, Zubieta MR, Colombo M, Arriaga JM, Bianchini M, Alperovich M, et al. MART-1- and gp100-expressing and -non-expressing melanoma cells are equally proliferative in tumors and clonogenic in vitro. J Invest Dermatol (2012) 132:365-74. doi:10.1038/jid.2011.312

28. Brandau S, Riemensberger J, Jacobsen M, Kemp D, Zhao W, Zhao X, et al. NK cells are essential for effective BCG immunotherapy. Int J Cancer (2001) 92:697-702. doi:10.1002/1097-0215(20010601)92:5<697:: AID-IJC1245>3.0.CO;2-Z

29. Kleinnijenhuis J, Quintin J, Preijers F, Joosten LAB, Jacobs C, Xavier RJ, et al. BCG-induced trained immunity in NK cells: role for non-specific protection to infection. Clin Immunol (2014) 155:213-9. doi:10.1016/j.clim. 2014.10.005

30. Steinman RM, Banchereau J. Taking dendritic cells into medicine. Nature (2007) 449:419-26. doi:10.1038/nature06175

31. Van Acker HH, Beretta O, Anguille S, De Caluwé L, Papagna A, Van Den Bergh JM, et al. Desirable cytolytic immune effector cell recruitment by interleukin-15 dendritic cells. Oncotarget (2016) 8:13652-65. doi:10.18632/ oncotarget. 14622

32. Sawant KV, Poluri KM, Dutta AK, Sepuru KM, Troshkina A, Garofalo RP, et al. Chemokine CXCL1 mediated neutrophil recruitment: role of glycosaminoglycan interactions. Sci Rep (2016) 6:33123. doi:10.1038/ srep33123

33. Kolaczkowska E, Kubes P. Neutrophil recruitment and function in health and inflammation. Nat Rev Immunol (2013) 13:159-75. doi:10.1038/nri3399

34. Wong KL, Tai JJ, Wong W, Han H, Sem X, Yeap W, et al. Gene expression profiling reveals the defining features of the classical, intermediate, and nonclassical human monocyte subsets. Blood (2011) 118:e16-31. doi:10.1182/ blood-2010-12-326355
35. Ziegler-Heitbrock L, Ancuta P, Crowe S, Dalod M, Grau V, Hart DN, et al. Nomenclature of monocytes and dendritic cells in blood. Blood (2010) 116:e74-80. doi:10.1182/blood-2010-02-258558

36. Lameijer MA, Tang J, Nahrendorf M, Beelen RHJ, Mulder WJM. Monocytes and macrophages as nanomedicinal targets for improved diagnosis and treatment of disease. Expert Rev Mol Diagn (2013) 13:567-80. doi:10.1586/ 14737159.2013.819216

37. Deshmane SL, Kremlev S, Amini S, Sawaya BE. Monocyte chemoattractant protein-1 (MCP-1): an overview. J Interferon Cytokine Res (2009) 29:313-25. doi:10.1089/jir.2008.0027

38. Palframan RT1, Jung S, Cheng G, Weninger W, Luo Y, Dorf M. Inflammatory chemokine transport and presentation in HEV: a remote control mechanism for monocyte recruitment to lymph nodes in inflamed tissues. J Exp Med (2001) 194:1361-73.

39. Pizzurro GA, Tapia IJ, Sganga L, Podhajcer OL, Mordoh J, Barrio MM Cytokine-enhanced maturation and migration to the lymph nodes of a human dying melanoma cell-loaded dendritic cell vaccine. Cancer Immunol Immunother (2015) 64:1393-406. doi:10.1007/s00262-015-1743-z

40. Mac Keon S, Gazzaniga S, Mallerman J, Bravo AI, Mordoh J, Wainstok R. Vaccination with dendritic cells charged with apoptotic/necrotic B16 melanoma induces the formation of subcutaneous lymphoid tissue. Vaccine (2010) 28:8162-8. doi:10.1016/j.vaccine.2010.09.095

41. Italiani P, Boraschi D. From monocytes to M1/M2 macrophages: phenotypical vs. functional differentiation. Front Immunol (2014) 5:514. doi:10.3389/ fimmu.2014.00514

42. Seneschal J, Clark RA, Gehad A, Baecher-Allan CM, Kupper TS. Human epidermal langerhans cells maintain immune homeostasis in skin by activating skin resident regulatory T cells. Immunity (2012) 36:873-84. doi:10.1016/ j.immuni.2012.03.018

43. Aris M, Bravo AI, Barrio MM, Mordoh J. Inoculation site from a cutaneous melanoma patient treated with an allogeneic therapeutic vaccine: a case report. Front Immunol (2015) 6:144. doi:10.3389/fimmu.2015.00144

44. Li Q, Normolle DP, Sayre DM, Zeng X, Sun R, Jiang G, et al. Immunological effects of BCG as an adjuvant in autologous tumor vaccines. Clin Immunol (2000) 94:64-72. doi:10.1006/clim.1999.4820

45. Banday AH, Jeelani S, Hruby VJ. Cancer vaccine adjuvants - recent clinical progress and future perspectives. Immunopharmacol Immunotoxicol (2015) 37:1-11. doi:10.3109/08923973.2014.971963

46. Walsh LJ, Trinchieri G, Waldorf HA, Whitaker D, Murphy GF. Human dermal mast cells contain and release tumor necrosis factor alpha, which induces endothelial leukocyte adhesion molecule 1. Proc Natl Acad Sci U S A (1991) 88:4220-4. doi:10.1073/pnas.88.10.4220

47. Pizzurro GA, Madorsky Rowdo FP, Pujol-Lereis LM, Quesada-Allué LA, Copati AM, Roberti MP, et al. High lipid content of irradiated human melanoma cells does not affect cytokine-matured dendritic cell function. Cancer Immunol Immunother (2013) 62:3-15. doi:10.1007/s00262-012-1295-4

48. Distler JHW, Schett G, Gay S, Distler O. The controversial role of tumor necrosis factor $\alpha$ in fibrotic diseases. Arthritis Rheum (2008) 58:2228-35. doi:10.1002/art.23645

49. Sziksz E, Pap D, Lippai R, Béres NJ, Fekete A, Szabó AJ, et al. Fibrosis related inflammatory mediators: role of the IL-10 cytokine family. Mediators Inflamm (2015) 2015:764641. doi:10.1155/2015/764641

50. Rubinstein N, Alvarez M, Zwirner NW, Toscano MA, Ilarregui JM, Bravo A, et al. Targeted inhibition of galectin-1 gene expression in tumor cells results in heightened T cell-mediated rejection. Cancer Cell (2004) 5:241-51. doi:10.1016/S1535-6108(04)00024-8

51. Zubieta MR, Furman D, Barrio M, Bravo AI, Domenichini E, Mordoh J. Galectin-3 expression correlates with apoptosis of tumorassociated lymphocytes in human melanoma biopsies. Am J Pathol (2006) 168:1666-75. doi:10.2353/ajpath.2006.050971

52. Pardo E, Cárcamo C, Martín RUS, Ciampi E, Segovia-Miranda F, Curkovic-Peña C, et al. Galectin-8 as an immunosuppressor in experimental autoimmune encephalomyelitis and a target of human early prognostic antibodies in multiple sclerosis. PLoS One (2017) 12:e0177472. doi:10.1371/ journal.pone.0177472

53. Guttlein LN, Benedetti LG, Fresno C, Spallanzani RG, Mansilla SF, Rotondaro C, et al. Predictive outcomes for HER2-enriched cancer using growth and metastasis signatures driven by SPARC. Mol Cancer Res (2016) 15:304-16. doi:10.1158/1541-7786.MCR-16-0243-T 
54. Wrzesinski SH, Wan YY, Flavell RA. Transforming growth factor- and the immune response: implications for anticancer therapy. Clin Cancer Res (2007) 13:5262-70. doi:10.1158/1078-0432.CCR-07-1157

Conflict of Interest Statement: The authors declare that the research was conducted in the absence of any commercial or financial relationships that could be construed as a potential conflict of interest.
Copyright (c) 2017 Pampena, Barrio, Juliá, Blanco, von Euw, Mordoh and Levy. This is an open-access article distributed under the terms of the Creative Commons Attribution License (CC BY). The use, distribution or reproduction in other forums is permitted, provided the original author(s) or licensor are credited and that the original publication in this journal is cited, in accordance with accepted academic practice. No use, distribution or reproduction is permitted which does not comply with these terms. 